\title{
Letters
}

\section{A tale of two Germanys}

\section{Health problems in eastern Germany are clearly related to transition}

EDITOR-The fall of the Berlin Wall in 1989 marked the beginning of the end of communism in eastern Europe and in eastern Germany. As McKee and Fister point out, ${ }^{1}$ certain constellations of epidemiological and demographic variables characterise the resultant process of political and economic transition: low or even decreasing life expectancy (especially for men) and higher prevalences of alcoholism and obesity. This has happened in the postcommunist Länder (federal states) of eastern Germany.

East Germany is different from other east European countries in that its healthcare sector was not deconstructed, with periods of severe dysfunction: it simply adopted the healthcare system of West Germany. Despite this, life expectancy at birth is still lower in eastern Germany than in western Germany, although the difference had diminished at the end of the $1990 \mathrm{s.}^{2}$

Alcoholic disease is a feature of the typical transition process. The number of people discharged from hospital with alcoholic disease was higher in eastern Germany in 1994 and 1999 than in western Germany. problem and a risk factor for many diseases. ${ }^{4}$ The proportion of the population with obesity (body mass index $>29.9$ ) is higher in eastern Germany than in western Germany. This difference has remained for over 10 years after the fall of the Berlin Wall.

In the medium term, the situation is set to even out. But it is remarkable that in spite of the same, well equipped (curative) health
Obesity is another transition related

system, health care does not strongly modify mainly lifestyle linked health effects in a population that is exposed to transition after communism. For eastern Germany, the end of this transition process is in sight.

\section{Friedrich Wilhelm Schwartz professor}

Schwartz.FW@mh-hannover.de

\section{Kurt Buser}

Hanover Medical School Department of Epidemiology, Social Medicine and Health System Research, Carl-Neuberg-Strasse 1, D-30625

Hanover, Germany

Competing interests: None declared.

1 McKee M, Fister K. Post-communist transition and health in Europe. BMJ 2004;329:1355-6.

2 Statistisces Bundest 10. Koordinierte Bevölkerungsvorausberechnung. 2003. 10. Koordinierte Bevölkerungsvorausberech
www.destatis.de/presse/deutsch/pk/2003/

bev 2050b.htm (accessed 14 Jul 2005).

3 Bundesministerium für Gesundheit und Soziales, Statistisches Bundesamt. Krankenhausstatistik-Diagnosen der Krankenhauspatienten. Gesundheitsberichterstattung des Bundes. www.destatis.de/download/qualitaetsberichte/ qualitaetsbericht_diagnosekhp.pdf (accessed 14 Jul 2005). 4 Robert Koch Institut. Gesundheitsberichterstattung. Berlin: RKI, 2003.

\section{Some patients in former East Germany} were more equal than others

EDITOR-Further to the comments by Schwartz and Buser (previous letter), selective treatment was carried out to a considerable extent in elderly people during the communist decades of East Germany (O Nehrlich, personal communication). ${ }^{1}$

If an elderly patient was in productive employment he or she was valuable to the system and deserving of medical treatment when needed. If the patient was retired and therefore a drain on the public purse the situation changed drastically. Diagnostic examinations such as radiography were

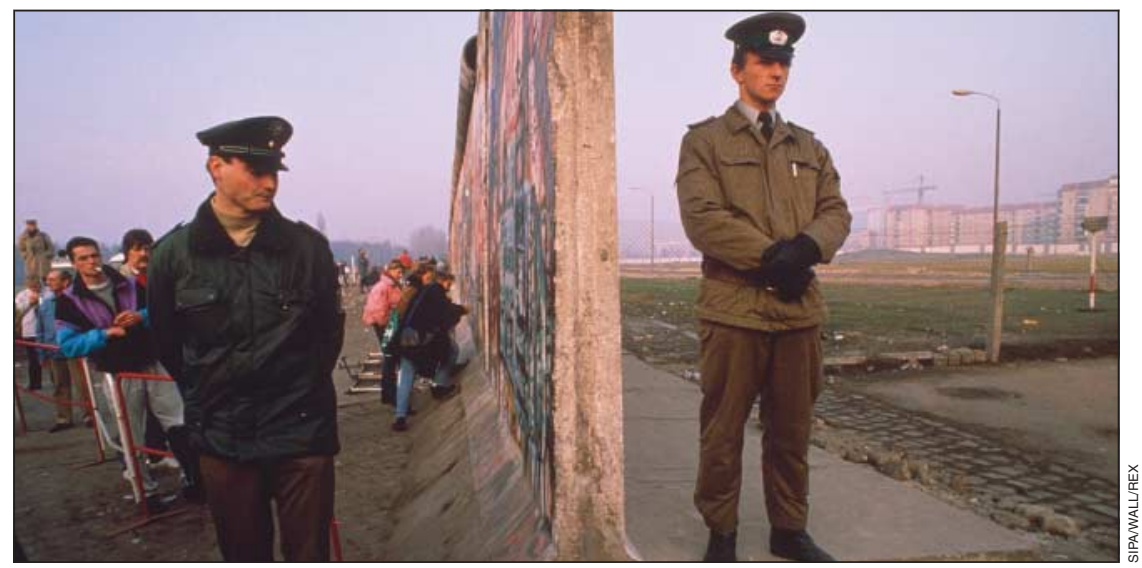

Transition-early phase often not done with the simple explanation that "at your age there is no need for $\mathrm{x}$ rays" (O Nehrlich, personal communication). People were not discouraged from travelling to the free world after retirement, and no one cared if they stayed there-purely an economic policy (O Nehrlich, personal communication). ${ }^{23}$

Life expectancy and health in general in the two regions, eastern and western Germany, ought to become similar gradually, although enough negative circumstances in the east prevail that still lead people to a higher consumption of alcohol, something that was not discouraged under the communist regime. It is also worth mentioning that programmes existed in East Germany to improve and maintain the health of people who were still working. Fitness was encouraged and subsidies for sports were freely available. Factory workers were given breaks during working hours, during which they exercised. All this applied only to those who were part of the workforce.

HHN lived in East Germany until September 1961, and his father, Otto Nehrlich, was a medical professor in the East German health system.

Competing interests: None declared.

Herbert $\mathbf{H}$ Nehrlich private practitioner Bribie Island, QLD 4507, Australia drhhnehrlich@westnet.com.au

1 Bollin C, Fischer-Bollin P. Mauer. In: Werner Weidenfeld W, Korte K-R, eds. Handbuch zur deutschen Einhei 1949-1989-1999. Bonn: Government of the Federa Republic of Germany, 1999:547-59.

2 Brockmann $\mathrm{H}$. Why is health treatment for the elderly less expensive than for the rest of the population? Health care rationing. Rostock: Max-Planck-Institut für demografisch Forschung, 2000. (MPIDR working paper.)

3 Deutsch-Deutscher Freiheitskampf '88--Fuer Freies Auswandern, Singen, Reisen, Beten. Marxistische Studentenzeitung. 3rd ed. Munich: Verein zur Foerderung des marxistischen Pressewesens, 1988.

\section{East Germany's health system provides} lessons 14 years on

EDIToR-Public health outcomes in East Germany have substantially improved since unification with West Germany. ${ }^{12}$ This process should be two way, ${ }^{3}$ and neglected aspects of the east's former healthcare system have indeed resurfaced in Germany's healthcare reform.

State owned health centres (policlinics) were one component of primary health care in former East Germany, housing general and specialist doctors and dentists. This integrated model was efficient and cost saving: facilities and laboratories were shared, alternative treatment and prevention strategies were coordinated, and referrals to specialists were well monitored, as well as each patient's case. Policlinics did not con- 
form to the west German concept of independently contracted doctors paid on the basis of an item of service, so they did not survive in east Germany after 1995, as predicted in 1992. ${ }^{4}$

In 2000 integrated healthcare centres were instigated in Germany's healthcare reform to increase cooperation between general doctors, specialists, and hospitals; to improve communication between institutions; and to reduce healthcare costs. ${ }^{5}$ Implementation has been slow because of traditional conflicts of interest and the lack of direct financial incentives, but recent legislation introduces the possibility of integrated healthcare centres being run by independent management companies.

These centres are similar to the policlinics of former East Germany. Had they survived they would have been a working example of how integrated healthcare centres can operate.

Dirk Meusel research associate

dirk.meusel@mailbox.tu-dresden.de

Ulf Maywald pharmaceutical doctor

Isabel Hach medical doctor

Wilhelm Kirch professor

Medical Faculty, Dresden University of Technology, D-01277 Dresden, Germany

Competing interests: None declared.

1 Nolte E, Shkolnikov V, McKee M. Changing mortality patterns in east and west Germany and Poland. II: Short-term trends during transition and in the 1990s.J Epidemiol $\mathrm{Com}^{-}$ munity Health 2000:54:899-906.

Pittrow D, Krappweis J, Rentsch A, Hach I, Schindler C, Bramlage P, Kirch W. Patterns of prescriptions issued by Bramlage $\mathrm{P}$, Kirch W. Patterns of prescriptions issued by nursing home based versus office-based physicians for frail elderly patients in German nursing homes. Pharmacoepidemiol Drug Safety 2003;12:595-9.

Nolte E. Integration of east Germany into the EU: Investment and health outcomes. In: McKee $\mathrm{M}$, MacLehose L, Nolte E, eds. Health policy and European Union enlargement. Maidenhead: Open University Press, 2004: 73-8

4 Freudenstein U, Borgwardt G. Primary medical care in former East Germany: the frosty winds of change. $B M J$ 1992;304:827-9

5 Bundesministerium für Gesundheit und Soziales. Sozialgesetzbuch: Fünftes Buch. www.bmgs.bund.de/download/ gesetze_web/gesetze.htm\#sgb05/sgb05xinhalt.htm (accessed 26 Jan 2005).

\section{Health care based on priorities is lost in decentralisation}

EDIToR-Decentralisation of the health system was applied in all transition countries in the 1990s. ${ }^{1-3}$ In most countries it was encouraged by the necessity to reform the inherited model of health organisation and to achieve the final goal-an efficient and fair health system. Croatia has special experience in decentralisation, primarily because of its geographical, political, and administrative circumstances but also because of its decentralised health system during the socialist regime in the 1980s.

Firstly, Croatia is a country with extreme differences between its regions. The income per head in the richest region is 10 times that in the poorest region.

Secondly, decentralisation reforms were not based on analyses of the problems and assessment of resources but on maintaining the framework within which they were implemented. Such implementation of the changes resulted in a complete change of the essence of the local health system, whereas the given framework imposed limitations on the development and changes, instead of fostering them.

Thirdly, decentralisation was implemented without having organised a local network of professionals that would work on the local level and would be able to manage local health needs.

Decentralisation is always a challenge in any health system and is mostly looked at as a series of political and organisational measures. Unfortunately, the expectation that decentralisation will ensure successful professional activities is often overlooked in the analyses. Furthermore, the measures and the purpose of decentralisation are often not recognised as important elements of political culture. The primary purpose of decentralisation-health care based on the real priorities and resources-therefore remains marginal.

Aleksandar Dzakula research fellow

Andrija Stampar School of Public Health,

Rockefellerova 4, Zagreb, Croatia

adzakula@snz.hr

Competing interests: None declared.

1 McKee M, Fister K. Post-communist transition and health in Europe. BMJ 2004;329:1355-6.

Fuenzalida-Puelma HL Health care reform in Central and Eastern Europe and the Former Soviet Union. Budapest: OS Eastern Europe and the Former Soviet Union. Budapest: OSI 2002:81-8.

3 Horvath MT, ed. Decentralization: experiments and reforms Budapest: OSI (Local Government and Public Services Reform Initiative), $2000 \cdot 15-8$

\section{Poland is losing its doctors}

EDITOR-The political transition in formerly communist countries has affected not only the health of their populations but also their healthcare systems. ${ }^{1}$ Healthcare reform introduced in Poland in 1999 influenced the organisation of health care, but the working environment of Poland's doctors has not improved. Since Poland's accession to the European Union, many doctors have left the country to look for jobs in west European countries, particularly the United Kingdom and Scandinavia (almost 500 Polish doctors registered in the UK in 2004, 30 times as many as in the previous year).

Why do so many doctors decide to leave their native country after democracy has been won?

Firstly, salaries are low, especially in hospitals - much lower than the average salary in public institutions (in a public hospital, doctors typically earn about $€ 300$ (£206; \$362) per month after tax). This is not enough to live on, so doctors (particularly young ones) cannot be fully independent and have to seek financial support from their families. Many cope with this problem by being employed in several places, and some work in the pharmaceutical industry (doctors working as sales representatives are probably rather unusual in other countries).

Secondly, the residency system is poorly developed, so after graduating many doctors are denied the possibility of specialisation.
Sometimes the only way to specialise in the chosen area is to emigrate from Poland. But not only financial reasons matter. The standard of living and the working conditions seem better in west European countries. Doctors can stick to just one job, which means shorter working time and fewer patients. In west European countries, access to new technologies of diagnosing and treating patients is much better. The variety of opportunities to develop professionally is also important, for clinicians as well as scientists.

Malgorzata M Bala PhD student

Jagiellonian University Medical College Institute of Public Health, Grzegorzecka 20, 31-531 Krakow,

Poland

gosiabala@mp.pl

Wiktoria M Lesniak assistant

Department of Medicine, Jagiellonian University School of Medicine, Skawinska 8,31-066 Krakow

Competing interests: None declared.

1 McKee M, Fister K. Post-communist transition and health in Europe. BMJ 2004;329:1355-6. (23 July.)

\section{Perindopril monotherapy and PROGRESS in Europe}

EDITOR-Perindopril has been registered in Poland as monotherapy for the prevention of recurrent stroke. The perindopril protection against recurrent stroke study (PROGRESS) is given as the only supporting evidence for this new indication, which is difficult to reconcile with the trialists' admission in the text of the publication that treatment with perindopril alone showed no discernible reduction in the risk of stroke.

Promotion of the new indication for perindopril is ongoing in Poland. Full page advertisements have run in Medycyna Praktyczna (issues 7-8/2004), announcing this "NEW INDICATION FOR USE," the capitalised words situated above a cartoon brain

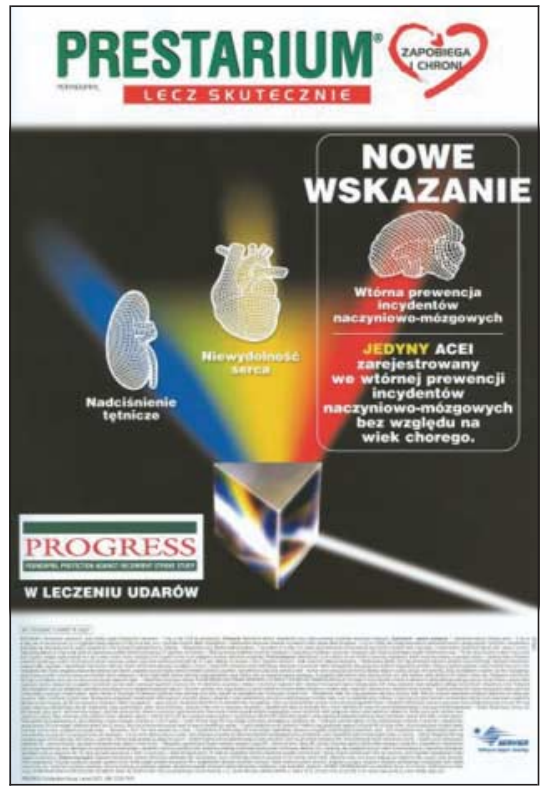

Polish advertisement for perindopril monotherapy 
Below the brain we read: "Secondary prevention of cerebrovascular incidents. THE ONLY ACEI registered for secondary prevention of cerebrovascular incidents in patients regardless of their age." Prominently displayed is the familiar PROGRESS logo.

No mention of indapamide is made in the prescribing instructions. No mention is made in the registration information that risk reduction in PROGRESS was seen only if indapamide was given in combination with perindopril.

In Italy, based on PROGRESS, perindopril (4 mg/day) has been granted a similar extended indication as monotherapy for the prevention of recurrent stroke. The Italian advertising inserts ignore the critical role of indapamide in PROGRESS. ${ }^{2}$ Yet in their BMJ commentary, the PROGRESS trialists admit that perindopril in monotherapy at $4 \mathrm{mg} /$ day provided no detectable benefits for prevention of recurrent stroke.

It is unclear how these registration mistakes may have arisen. Both perindopril and indapamide are manufactured by Servier, a sponsor of the PROGRESS trial (perindopril is currently under patent protection; indapamide is no longer protected by patent). It is possible that the promoters of perindopril in these countries have misunderstood the findings of the PROGRESS trial. Whatever the origins of the mistakes, they are problematic sequelae of the ambiguously reported clinical trial data. ${ }^{4}$

Richard Wennberg associate professor Richard.Wennberg@uhn.on.ca

Camilla Zimmermann assistant professor

University of Toronto, University Health Network, Toronto, Canada M5T 2S8

Competing interests: None declared.

1 PROGRESS Collaborative Group. Randomised trial of a perindopril-based blood-pressure-lowering regimen among 6,105 individuals with a previous stroke or transient ischaemic attack. Lancet 2001;358:1033-41.

2 Bobbio M, Della Penna V, Tarascio A. Inchiesta sull'indicazione terapeutica del perindopril. Dall'evidence based medicine all'advertisment based medicine. Occhio Clinico 2005;3:6

3 MacMahon S, Neal B, Rodgers A, Chalmers J. Commentary. The PROGRESS trial three years later: time for more action, less distraction. BMJ 2004;329:970-1.

4 Wennberg R, Zimmermann C. The PROGRESS trial three years later: time for a balanced report of effectiveness. $B M$ 2004:329:968-70.

\section{From the former Soviet Union}

\section{Maternal education seems to determine pregnancy outcomes in Russia}

EDITOR-Social resilience is the ability of human communities to withstand and recover from external shocks or disturbances to their infrastructure. The countries of the former Soviet Union seem to have been more vulnerable to the recent political, economic, and social changes than the countries of central Europe, which are showing signs of recovery from the crisis.

Although the changes have been more profound in the former Soviet republics than in central Europe, social determinants of health in the former Soviet countries have received less attention. For example, no

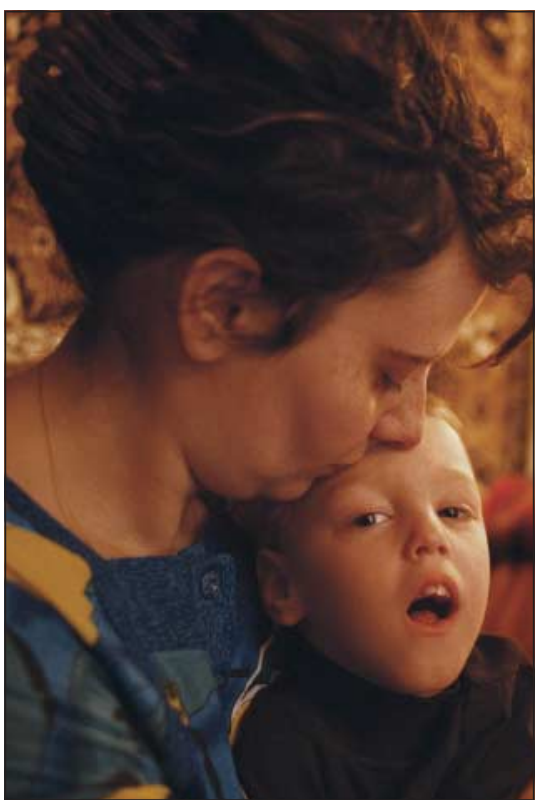

Maternal factors strongly influence pregnancy outcomes in Russia

studies on socioeconomic determinants of maternal and child health based on Russian data have been published in international, peer reviewed journals.

We studied social determinants of pregnancy outcomes and infant growth in Severodvinsk, a town in northwest Russia, one of the regions that have suffered most since 1990. ${ }^{1}$ All 1559 pregnant women registered at municipal antenatal clinics during 1999 were enrolled in a cohort and followed through delivery. Their infants were followed up during the first year of life.

Social variations in birth weight ${ }^{2}$ and preterm birth rates ${ }^{3}$ were among the largest in Europe. Maternal education was the most important social factor influencing pregnancy outcomes in the area, even after suspected explanatory mechanisms were included in the analyses. Poor housing conditions, stress, and smoking also influenced fetal growth indices. ${ }^{4}$ Variations in linear growth of infants by maternal education tended to increase during the first year of life.

Evidence of the existence of social inequalities in health is an important first step towards addressing these problems. It advocates the development of policies designed to reduce these inequalities. From a scientific perspective, larger, well designed studies are needed to reveal the mechanisms behind the large social disparities in pregnancy outcomes in Russia.

Andrej M Grjibovski post-doctoral research fellow Division of Epidemiology, Norwegian Institute of Public Health, Post box 4404 Nydalen, 0403 Oslo, Norway

andrej.grjibovski@prevnut.ki.se

Lars Olov Bygren professor emeritus

Department of Biosciences at Novum, Karolinska Institutet, 14157 Huddinge, Sweden

A full text copy of the thesis by AMG, entitled "Sociodemographic determinants of pregnancy outcomes and infant growth in transitional Russia," is available by emailing him.

Competing interests: None declared.
1 Walberg P, McKee M, Shkolnikov V, Chenet L, Leon DA. Economic change, crime, and mortality crisis in Russia: regional analysis. BMJ 1998:317:312-8.

Cijbovsi AM, By Grjibovski AM, Bygren LO, Svartbo B, Magnus P. Socia variations in fetal growth in a Russian setting: an analysi 2003;9:599-605

3 Grjibovski AM, Bygren LO, Svartbo B, Magnus P. Housing conditions, perceived stress, smoking, and alcohol - determinants of fetal growth in northwest Russia. Acta Obstet

4 Grjibovski AM, Bygren LO, Yngve A, Sjöström M. Large social disparities in spontaneous preterm births in social disparities in spontaneous preterm birth

5 transitional Russia. Public Health 2005; 119:77-86. Grjibovski AM, Bygren LO, Yngve A, Sjöström M. Socia variations in infant growth performance in Severodvinsk, northwest Russia: community-based cohort study. Croat
Med J 2004;45:757-63.

Socioeconomic health inequalities exist in post-communist Lithuania

EDITOR-With regard to the health problems highlighted by McKee and Fister, socioeconomic differences and changes are relevant contributors for health policy makers in Lithuania. Lithuania is characterised not only by a high level of social inequality but also by low social care expenditure. Social care expenditure comprises 25-35\% of gross national product in European Union countries, whereas it accounts for only about $15 \%$ in Lithuania. The income inequality indicator (Gini coefficient) was $35.4 \%$ in 2002 . $^{2}$ Social inequality has been strongly influenced by the fact that even $17 \%$ of the working population is engaged in agriculture and nearly one third of the rural population lives in rural districts.

According to our data analysis, the prevalence of self reported health problems is $72.2 \%$ in the rural population and $60.3 \%$ in the urban population. A higher prevalence of self reported health problems $(69.7 \%)$ was estimated in women than in men $(57.6 \%)$. The prevalence of health problems was dependent on social structure: it was higher in women than in men and in the rural population than in the urban population. For the low income rate, the prevalence of health problems was 3.9 times higher in the rural population and 2.4 times higher in the urban population. The prevalence of health problems at low and high income levels was 3.2 times higher in women and 2.3 times higher in men.

Health inequalities between urban and rural populations are predetermined by a different income level related to investments, market opportunities, and social care possibilities.

Differentiation and essential differences in socioeconomic changes between urban and rural populations have the pivotal role in health inequalities in post-communist Lithuania.

Antanas Jurgelenas senior research worker antanas.jurgelenas@ekmi.vu.lt

Diana Mieliauskaite $P h D$

Rima Filipaviciute $P h D$

Institute of Experimental and Clinical Medicine at Vilnius University, Zygimantu 9, LT-01102, Vilnius, Lithuania

Competing interests: None declared.

1 McKee N, Fister K. Post-communist transition and health in Europe. BMJ 2004;329:1355-6. (11 December.) 2 Lazutka R. [Population's income inequality]. In Lithuanian. Filosofija Sociologija 2003;2:22-9. 


\section{Georgia to Georgia initiative}

EDITOR-A consortium of academic communities in the US city of Atlanta, Georgia (Emory University, Georgia State, Georgia Tech, Grady Hospital, and Morehouse School of Medicine) has been working with a similar group and the health ministry for the former Soviet country of Georgia since 1992. This partnership has produced several accomplishments:

- Forty medical school graduates of Georgia have received postgraduate specialty training or their MPH degrees in Atlanta

- A Western-type BBA and MBA school was established in Tbilisi, Georgia's capital, and a faculty of 63 Georgians trained in Atlanta teaches a student body of 800

- A learning centre teaches healthcare workers how to find up to date medical information on the internet

- Nursing school and healthcare management schools staffed by Georgians trained in Atlanta are being established

- A women's wellness centre in Kutaisi teaches breast health, perinatal care, preventive health care, and reproductive counselling

- The research infrastructure of the country is being built up with collaborative activities in AIDS and tuberculosis funded by the National Institutes of Health

- Young Georgian scientists receiving training in Atlanta are being taught how to be competitive for grants

- A training centre for emergency medical services was established and trains hundreds of policemen, firemen, and others in resuscitation at the scene of an incident. Numerous student exchanges have occurred between Atlanta and Tbilisi

- One medical student in Atlanta showed that $64 \%$ of newborn infants in Tbilisi had hypothyroidism because of a lack of iodinated salt in the country, resulting in corrective efforts by the government of Georgia and international organisations.

The partnership illustrates that academic communities provide a uniquely rich resource for establishing sustainable, long term development and reform in countries exemplified by Georgia; information technology has been a key resource for this effort; and Georgia's geographical position produces a fertile environment for broadening the scope of knowledge crucial for establishing sustainable development programmes in regions characterised by diversity and instability.

These activities have received funding from the US Agency for International Development and other organisations.

H Kenneth Walker professor of medicine

Emory University School of Medicine, 69 Jesse Hill

Jr Drive SE, No 202, Atlanta, GA 30303, USA

kwalk04@emory.edu

\section{Bijan Falollahi professor}

Georgia State University, Institute of International Business, 35 Broad Street, Atlanta, GA 30303, USA

Zviad Kirtava director

National Information Learning Centre, Tbilisi, Georgia
Judith Wold associate professor

Georgia State University, College of Health and Human Services - School of Nursing, MSC 2A0965, 33 Gilmer Street SE, Atlanta, GA 30302-4019, USA

Competing interests: None declared.

\section{Nuclear weapons are another post-communist health hazard}

EDITOR-In their editorial McKee and Fister highlight many of the major health issues in the post-communist countries of Europe. Another critical threat to health is the nuclear weapons in various European countries, and particularly Russia. According to a recent estimate, Russia has 7800 operational nuclear warheads in its arsenal, ${ }^{2}$ of which about 4400 are strategic warheads. This relic of the cold war poses risks of accidental explosions or of missile launches, since some of these weapons are on high alert status. There is also a risk that actual weapons and fissile materials associated with them could be stolen and sold to terrorists. Maintaining the system for producing and maintaining nuclear weapons is also a drain on national economies-with fewer financia resources available for health and other essential services.

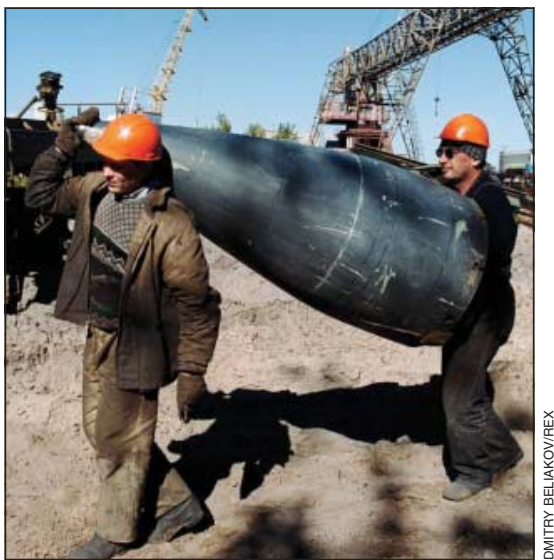

Good riddance

European countries need to accelerate progress towards a Europe that is free of nuclear weapons. In particular, the relevant countries (Russia, France, and the United Kingdom) need to meet their obligations for nuclear disarmament under the Nuclear Non-Proliferation Treaty. Other European countries that have US nuclear weapons on their territories (Belgium, Germany, Italy, Netherlands, and Turkey ${ }^{3}$ ) need to follow Greece (another member of the North Atlantic Treaty Organisation) in having these removed. Without such actions, European and other populations will continue to be threatened by weapons that are not able to deal with the real security threats now facing the world.

Nick Wilson senior lecturer, public health Wellington School of Medicine, Otago University, Wellington, New Zealand nwilson@actrix.gen.nz
Competing interests: NW is an active member of International Physicians for the Prevention of Nuclear War (IPPNW)-New Zealand branch.

1 McKee M, Fister K. Post-communist transition and health in Europe. BMJ 2004;329:1355-6.

2 Norris RS, Kristensen HM. Russian nuclear forces, 2004 Bull Atomic Scientists 2004;60:72-4. www.thebulletin.org/ article_nn.php?art_ofn $=$ ja04norris (accessed 7 Jul 2005) 3 Norris RS, Kristensen HM. U.S. nuclear weapons in Europe, 1954-2004. Bull Atomic Scientists 2004;60:76-7. www.thebulletin.org/article_nn.php?art_ofn $=$ nd04norris (accessed 7 Jul 2005)

TB in immigrants is not public health risk, but uncontrolled epidemics are

EDITOR-Before the second world war no medicines existed to cure tuberculosis (TB). Only 50 years later, strains of tuberculosis that are resistant to all major drugs have emerged. ${ }^{1}$ Many areas of the former Soviet Union have been found to harbour high incidences of multidrug resistant tuberculosis. ${ }^{1}$ In many Western countries, an increasing number of cases of tuberculosis in foreign born residents has resulted in a change from the expected downward trend. ${ }^{2}$

Over the past years, increasing numbers of people have left the new states of the former Soviet Union. In neighbouring Scandinavian countries there is public concern that increased immigration may result in increased transmission of infectious diseases, such as multidrug resistant tuberculosis. More than 30000 former Soviet citizens have arrived in Norway since 2001. ${ }^{3}$ Only four of these were diagnosed with multidrug resistant tuberculosis on arrival, and their infections were not transmitted to other people in Norway. ${ }^{4}$

Little evidence exists that increased immigration and imported tuberculosis threaten public health in the neighbouring countries of the former Soviet Union. Tuberculosis is rarely transmitted from immigrants, ${ }^{245}$ and, from a global point of view, it is far more threatening to the public health if epidemics are uncontrolled than it is to take part in controlling them. So long as tuberculosis remains a major health problem in some parts of the world, no country can expect to eliminate this disease.

Ulf R Dahle senior scientist

Norwegian Institute of Public Health, PO Box 4404 Nydalen, 0403 Oslo, Norway

ulf.dahle@fhi.no

Competing interests: None declared.

1 Toungoussova OS, Mariandyshev AO, Bjune G, Caugant DA, Sandven P. Resistance of multidrug-resistant strains of Mycobacterium tuberculosis from the Archangel oblast, Russia, to second-line anti-tuberculosis drugs. Eur J Clin Microbiol Infect Dis 2005;24:202-6.

2 Dahle UR, Sandven P, Heldal F, Caugant D. Continued low rates of transmission of Mycobacterium tuberculosis in Norway. J Clin Microbiol 2003;41:2968-73.

3 Statistics Norway. Immigrant population, by sex and counStatistics Norway. Immigrant population, by sex and counry background. http://statbank.ssb.no// statistikkbank

defalt 1 . asp? Tanguage $=1$ (accessed $6 \mathrm{Jul} 2005)$.

Winje BA, Mannsaaker 1, Heldal E, Blystad H, Dahle UR. Tuberculosis in Norway 2004. MSIS report 2005;33:26 (ww).hi.no/dav/DFT T5348.PDF). [n Norwegian.] Winje BA, Mannsaaker T, Blystad H, Dahle UR. Tuberculosis in Norway 2003. MSIS report 2004;32:32. (www.fhi.no/ dav/A5FE92684F.PDF). [In Norwegian.] 